\title{
PENGARUH BUDGET EMPHASIS, SELF ESTEEM, DAN PARTISIPASI ANGGARAN TERHADAP BUDGETARY SLACK PADA OPD PEMERINTAH KABUMATEN KEBUMEN
}

\author{
Eka Fitria Ambarini, Mispiyanti \\ Sekolah Tinggi Ilmu Ekonomi Putra Bangsa
}

eka.fitria.ambarini1@gmail.com

\begin{abstract}
Abstrak
Budgetary slack timbul apabila manajer sengaja menetapkan pendapatan terlalu rendah atau menetapkan biaya terlalu besar. Kondisi yang dapat menyebabkan timbulnya budgetary slack adalah adanya budget emphasis, self esteem dan partisipasi anggaran. Penelitian ini bertujuan untuk menguji pengaruh budget emphasis, self esteem, dan partisipasi anggaran terhadap budgetary slack. Penelitian ini menggunakan data primer yang diperoleh dengan menyebarkan kuesioner ke responden. Populasi penelitian ini adalah OPD Kabupaten Kebumen dengan teknik pengambilan sampel menggunakan pusposive sampling. Dari 75 kuesioner yang dibagikan, hanya 70 kuesioner yang diterima kembali, dan hanya 43 kuesioner yang dapat diproses. Penelitian ini menggunakan metode analisis regresi berganda. Berdasarkan hasil uji t menunjukkan bahwa: (1) budget emphasis berpengaruh positif dan signifikan terhadap budgetary slack. (2) self esteem berpengaruh dan signifikan terhadap budgetary slack. (3) partisipasi anggaran tidak berpengaruh signifikan terhadap budgetary slack. Sedangkan uji f menunjukkan bahwa budget emphasis, self esteem, dan partisipasi anggaran bersama - sama berpengaruh terhadap budgetary slack pada OPD Kabupaten Kebumen. Koefisien determinasi $\left(\mathrm{R}^{2}\right)$ diperoleh hasil $29,5 \%$, artinya $29,5 \%$ variabel budget emphasis dipengaruhi oleh variabel budget emphasis, self esteem, dan partisipasi anggaran, sedangkan sisanya sebesar 70,5\% dijelaskan oleh variabel lain yang tidak ada dalam penelitian ini.
\end{abstract}

Kata kunci : Budget Emphasis, Self Esteem, Partisipasi Anggaran, Budgetary Slack

\section{Abstract}

Budgetary slack appears when managers intentionally determine a lower income or higher cost pricing. That was caused by the presence of budget emphasis, self esteem and budget participation. Therefore, the study aimed to examine the causal relationship between budget emphasis, self esteem and budget participation by using primary data which collected by distributing questionnaires to respondent. The population was OPD Regency of Kebumen with a purposive sampling as sampling technique. From 75 questionnaires that have been distributed, 70 questionnaires have been received and only 43 questionnaires that could be processed. This studied used multiple regression analysis method. The study showed that based on t test: (1) budget emphasis has a positive and significant effect on budgetary slack (2) self esteem has a positive and significant effect on budgetary slack, and (3) budget participation has not significant effect on budgetary slack. Mean while based on $f$ test budget emphasis, self esteem, and budget participation collectively affect the budgetary slack to the OPD Regency of Kebumen. The coefficient on determination $\left(R^{2}\right)$ showed $29,5 \%$, that was mean $29,5 \%$ variable of budgetary slack influenced by variables budget emphasis, self esteem, and budget participation but 70,5\% explained by other variable which not exist in this research.

Keywords : Budget Emphasis, Self Esteem, budget participation, Budgetary Slack.

\section{PENDAHULUAN}

Pemberlakuan otonomi daerah sebagaimana yang diatur dalam UU No. 23 Tahun 2014 kemudian diperbarui UU No. 9 Tahun 2015, membuat pemerintah daerah Kabupaten Kebumen ikut melakukan perubahan sistem, dari sistem anggaran tradisional (traditional budget system) menjadi sistem berbasis kinerja (performance budget system). Sistem penganggaran dapat dilakukan dengan metode top down, bottom up, dan gabungan keduanya, Halim dan Iqbal (2012). Anggaran yang disusun secara bottom-up menyebabkaan informasi mengenai komponen dalam anggaran 


\section{PENGARUH BUDGET EMPHASIS, SELF ESTEEM, DAN PARTISIPASI ANGGARAN TERHADAP BUDGETARY SLACK PADA OPD PEMERINTAH KA BUPATEN KEBUMEN}

lebih diketahui oleh manajemen tingkat bawah (lower level manager). Setiyanto (2011) menyebutkan dalam penelitian Christensen (1982), Merchant (1985), Pope (1984) dan Young (1985) menunjukkan bahwa bawahan yang merahasiakan informasi yang relevan dalam pembuatan anggaran akan menimbulkan budgetary slack.

Budgetary slack atau kesenjangan anggaran merupakan sebuah perilaku disfungsional. Indikasi adanya budgetary slack baru dapat dinilai pada saat anggaran direalisasikan, Dewi (2008). Slack terjadi apabila realisasi pendapatannya cenderung lebih tinggi dari target yang ditetapkan dalam anggaran dan realisasi belanja cenderung lebih rendah dari target yang telah ditetapkan. Hal ini dapat dilihat pada tabel Anggaran dan Realisasi Pendapatan dan Belanja Daerah OPD Pemerintah Daerah Kabupaten Kebumen tahun 2012- 2016.

Tabel 1 Realisasi Pendapatan dan Belanja Daerah OPD Pemerintah Kabupaten Kebumen Tahun 2012-2016

\begin{tabular}{|c|c|c|c|c|c|c|}
\hline Th. & $\begin{array}{c}\text { Target Anggaran } \\
\text { Pendapatan } \\
\text { Daerah } \\
\text { (Dalam 000) } \\
\end{array}$ & $\begin{array}{c}\text { Realiasi } \\
\text { Pendapatan } \\
\text { Daerah } \\
\text { (Dalam 000) } \\
\end{array}$ & $\%$ & $\begin{array}{l}\text { Target Anggaran } \\
\text { Belanja Daerah } \\
\text { (Dalam 000) }\end{array}$ & $\begin{array}{c}\text { Realiasi Belanja } \\
\text { Daerah }\end{array}$ & $\%$ \\
\hline & (a) & (b) & $(\mathrm{b} / \mathrm{a}) * 100$ & (c) & (d) & $(\mathrm{c} / \mathrm{d}) * 100$ \\
\hline 2012 & Rp1,272,818,544 & $\mathrm{Rp} 1,273,275,623$ & 100,04 & $\mathrm{Rp} 1,300,293,217$ & Rp1,216,956,106 & $93,59 \%$ \\
\hline 2013 & Rp1,599,628,126 & Rp1,626,530,654 & 101,68 & Rp1,704,544,615 & Rp1,548,176,706 & $90,83 \%$ \\
\hline 2014 & $\mathrm{Rp} 1,875,551,127$ & Rp1,967,047,779 & 104,88 & $\mathrm{Rp} 2,050,427,145$ & Rp1,906,501,957 & $92,98 \%$ \\
\hline 2015 & Rp1,972,960,045 & $\mathrm{Rp} 2,326,188,256$ & 117,90 & Rp2,039,879,752 & Rp2,033,106,110 & $99,67 \%$ \\
\hline 2016 & Rp2,779,114,760 & Rp2,606,209,824 & 93,78 & Rp2,614,927,866 & Rp2,283,531,796 & $87,33 \%$ \\
\hline
\end{tabular}

Sumber : www.kebumenkab.go.id/index.php/public/page/index/73

Berdasarkan data tersebut diindikasi adanya budgetary slack ditahun 2012-2016 pada OPD Pemerintah kabupaten Kebumen. Terlihat pada persentase pencapaian pendapatan yang lebih dari $100 \%$ dan pada realisasi belanja kurang dari $100 \%$ artinya terdapat penghematan biaya.

Budget emphasis adalah kondisi dimana anggaran dijadikan faktor yang paling dominan dalam pengukuran kinerja bawahan pada suatu organisasi, Kahar dan Hormati (2017). Bawahan akan senantiasa berusaha meningkatkan kinerjanya diantaranya dengan meningkatkan performance sehingga realisasi anggaran lebih tinggi dibandingkan dengan target yang dibuat dan dengan melonggarkan anggaran pada saat penyusunan anggaran.

Self esteem adalah suatu keyakinan nilai diri sendiri berdasarkan evaluasi diri secara keseluruhan. Apabila self esteem seseorang tinggi maka akan cenderung mempertahankan nilai dirinya, untuk memastikan nilai yang baik bisa saja seseorang akan melakukan disfungsional salah satunya budgetary slack.

Faktor lain yang dianggap memiliki pengaruh pada timbulnya budgetary slack adalah partisipasi anggaran. Menurut Muharrom, (2014) dalam Basyir (2016) partisipasi anggaran adalah partisipasi aktif unit - unit organisasi mulai level bawah sampai atas dalam menyampaikan target anggaran yang 


\section{PENGARUH BUDGET EMPHASIS, SELF ESTEEM, DAN PARTISIPASI \\ ANGGARAN TERHADAP BUDGETARY SLACK PADA OPD \\ PEMERINTAH KA BUPATEN KEBUMEN}

disusun. Pihak eksekutif cenderung mengajukan anggaran dengan merendahkan pendapatan dan menaikan biaya dibandingkan dengan estimasi terbaik dari yang diajukan, sehingga target akan lebih mudah tercapai. Hal ini dapat berdampak buruk pada organisasi sektor publik.

Berdasarkan uraian diatas penelitian ini bertujuan untuk mengetahui pengaruh budget emphasis, self esteem, dan partisipasi anggaran terhadap budgetary slack pada OPD pemerintah Kabupaten Kebumen.

\section{TINJAUAN PUSTAKA}

\section{Teori Agensi}

Teori agensi merupakan teori yang mempelajari hubungan atau keterkaitan pihak pihak yang memiliki jalinan hubungan fungsional dan struktural, yaitu antara prinsipal dan agen. Menurut Jense dan Meckling (1976) dalam Basyir (2016), teori keagenan adalah konsep yang menjelaskan hubungan kontraktual antara prinsipal dan agen, yaitu antara dua pihak atau lebih individu, kelompok, atau organisasi. Agen dan prinsipal diasumsikan termotivasi oleh kepentingannya sendiri, konflik kepentingan antara agen dan prinsipal akan terus meningkat, karena prinsipal tidak dapat memonitor kegiatan agen setiap hari. Sebaliknya, agen memiliki lebih banyak informasi penting mengenai kapasitas diri, lingkungan kerja, dan organisasinya secara keseluruhan, Basyir (2016). Hal inilah yang menimbulkan informasi asimetri yaitu ketidakseimbangan informasi antara prinsipal dan agen dan memicu terjadinya budgetary slack.

\section{Budgetary Slack}

Budgetary slack merupakan tindakan bawahan yang mengecilkan kapabilitas produktifnya ketika bawahan diberi kesempatan untuk menentukan standar kinerjanya, Darlis (2002) dalam Arthaswadaya (2015:21). Budgetary slack merupakan representasi berbagai upaya yang dilakukan oleh para manajer untuk menyesuaikan anggaran yang lebih didasarkan pada kepentingan pribadi. Budgetary slack umumnya terlihat pada biaya yang ditinggikan, pendapatan yang dikecilkan, atau estimasi dibawah kemampuan kinerja yang seharusnya, Shiff dan Lowin (1970) dalam Setiyanto (2011:14).

\section{Hubungan Budget Emphasis dan Budgetary Slack}

Budget emphasis adalah pemberian reward atau penilaian kinerja bagi para manajer menengah ke bawah berdasarkan pada pencapaian target anggaran, atau apabila para manajer mempersepsikan bahwa kinerja dan penghargaannya dinilai berdasarkan pada target anggaran yang dicapai, Dunk (1993) dalam Guswandi (2017:21).

Manajer tingkat bawah berusaha melakukan slack adalah untuk meningkatkan kesempatan memperoleh penghasilan yang lebih apabila penghargaan yang diberikan ditandai dengan pencapaian anggaran, maka mereka akan cenderung membangun senjangan dalam anggarannya melalui proses partisipasi, Waller (1988) dalam Kahar dan Hormati (2017:77).

Berdasarkan hasil penelitian Guswandi (2017) serta Wati dan Damayanthi (2017) membuktikan bahwa budget emphasis berpengaruh positif dan signifikan terhadap budgetary slack. Hal ini berarti, bahwa adanya tekanan anggaran menyebabkan terjadinya budgetary slack karena bawahan akan selalu ingin kinerjanya terlihat baik.

$\mathbf{H}_{\mathbf{1}}$ : Budget Emphasis berpengaruh positif terhadap Budgetary Slack.

\section{Hubungan Self Esteem dan Budgetary Slack}

Self esteem adalah suatu perasaan keberhargaan seseorang atas dirinya sendiri dan sejauh mana seseorang tersebut mengenal diri pribadi mereka. Biasanya seseorang dengan self 


\section{PENGARUH BUDGET EMPHASIS, SELF ESTEEM, DAN PARTISIPASI \\ ANGGARAN TERHADAP BUDGETARY SLACK PADA OPD \\ PEMERINTAH KA BUPATEN KEBUMEN}

esteem yang tinggi termotivasi untuk melakukan pekerjaannya dengan baik untuk menjaga konsistensi hasil evaluasi dirinya agar tetap baik, Ferris et al (2010) dalam Ardanari dan Putra (2014). Namun, karena selalu termotivasi untuk memperlihatkan dan memastikan nilai dirinya baik, bisa saja seseorang melakukan disfungsional. Hal inilah yang memicu terjadinya budgetary slack.

Berdasarkan hasil penelitian Bangun dan Andani (2012) membuktikan bahwa self esteem berpengaruh signifikan terhadap budgetary slack dan memiliki hubungan yang positif. Artinya semakin tinggi self esteem semakin tinggi pula peluang terjadinya budgetary slack. Artinya semakin tinggi self esteem semakin tinggi pula peluang terjadinya budgetary slack.

$\mathbf{H}_{2}$ : Self Esteem berpengaruh positif terhadap Budgetary Slack.

\section{Hubungan Partisipasi Anggaran dan Budgetary Slack}

Partisipasi merupakan suatu proses pengambilan keputusan bersama oleh dua pihak atau lebih yang membawa efek di masa yang akan datang bagi mereka yang membuat keputusan, Becker et al (1978) dalam Setiyanto (2011:24). Arthaswadaya (2015:17) menyatakan bahwa partisipasi anggaran adalah proses dimana bawahan/pelaksana anggaran diberikan kesempatan untuk terlibat, dan mempunyai pengaruh dalam proses penyusunan anggaran.

Manajer yang memiliki tingkat keterlibatan kerja (partisipasi) yang tinggi mengidentifikasikan bahwa mereka memelihara pekerjaannya. Karena akan dinilai kinerjanya berdasarkan anggaran hal ini akan memiliki kecenderungan yang lebih tinggi pula bagi manajer untuk menciptakan budgetary slack.

Berdasarkan hasil penelitian Basyir (2016) membuktikan bahwa partisipasi anggaran berpengaruh positif dan signifikan terhadap budgetary slack. Ketika partisipasi anggaran yang dilakukan oleh bawahan semakin besar, maka akan menimbulkan budgetary slack yang semakin besar pula.

$\mathbf{H}_{3}$ : Partisipasi Anggaran berpengaruh positif terhadap Budgetary Slack.

$\mathbf{H}_{\mathbf{4}}$ : Budget Emphasis, Self Esteem, Partisipasi Anggaran secara simultan berpengaruh terhadap Budgetary Slack.

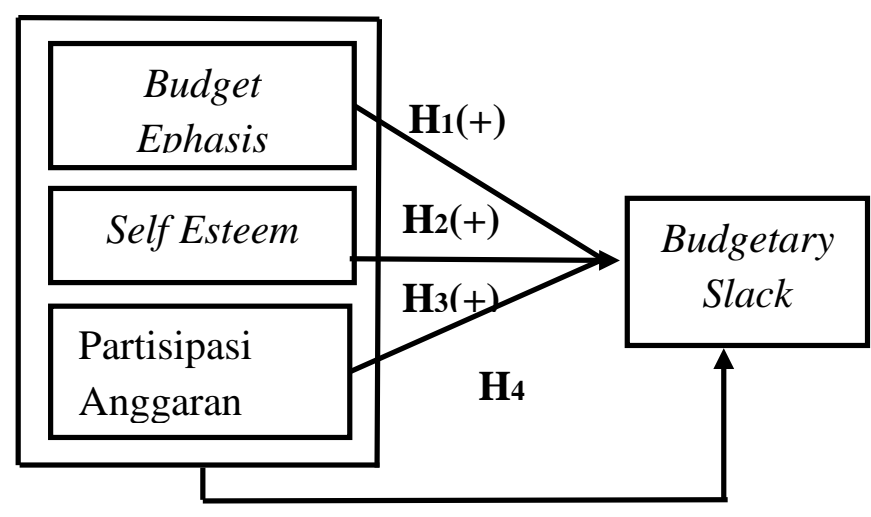

\section{METODE PENELITIAN}

Populasi dalam penelitian ini yaitu seluruh Organisasi perangkat daerah (OPD) di Kabupaten kebumen yang berjumlah 25 OPD. Sedangkan sampel yang digunakan yaitu purposive sampling, dimana sampel ditentukan dengan pertimbangan atau kriteria tertentu.

Penelitian ini menggunakan data primer. Metode yang digunakan untuk memperoleh data dari responden yaitu metode survey dengan menggunkan kuesioner yang berisi sejumlah pertanyaan yang berkaitan dengan budget emphasis, self esteem, partisipasi anggaran dan budgetary slack. Teknik skala pengukuran menggunakan skala likert. Dengan skala likert, jawaban setiap item instrument dinilai dari sangat setuju sampai sangat tidak setuju dari skala 1 sampai 4.

\section{Pengukuran Variabel}

Pengukuran variabel budget emphasis diukur dengan kuesioner yang diadopsi dari Asak (2014) dalam Guswandi (2017) yang terdiri dari enam item pertanyaan, instrument ini 


\section{PENGARUH BUDGET EMPHASIS, SELF ESTEEM, DAN PARTISIPASI \\ ANGGARAN TERHADAP BUDGETARY SLACK PADA OPD \\ PEMERINTAH KA BUPATEN KEBUMEN}

juga pernah digunakan dalam penelitiannya Nurrasyid (2015) dan Mulyani (2015).

Pengukuran variabel self esteem diukur dengan kuesioner yang diadopsi dari Rosenberg (1965) dalam Arthaswadaya (2015) yang terdiri dari sepuluh item pertanyaan, instrument ini juga pernah digunakan dalam penelitiannya Guswandi (2017) dan Azwar (2003).

Pengukuran variabel partisipasi anggaran diukur dengan kuesioner yang diadopsi dari Milani (1975) dalam Apriyandi (2011) yang terdiri dari enam item pertanyaan, instrument ini juga pernah digunakan dalam penelitiannya Anggraeni (2008) serta Kahar dan Hormati (2017).

Pengukuran variabel budgetary slack diukur dengan kuesioner yang diadopsi dari Dunk (1993) dalam Apriyandi (2011) yang terdiri dari enam item pertanyaan, instrument ini juga pernah digunakan dalam penelitiannya Anggraeni (2008) dan Guswandi (2017).

\section{HASIL PENELITIAN}

\section{Uji Validitas dan Reliabilitas}

Hasil uji validitas dan reliabilitas menunjukkan bahwa instrument penelitian harus valid dan reliabel.

Tabel 2 Uji Validitas

\begin{tabular}{lcccc}
\hline Variabel & Item & $\begin{array}{c}\mathbf{R} \\
\text { Hitung }\end{array}$ & $\begin{array}{c}\mathbf{R} \\
\text { Tabel }\end{array}$ & Keterangan \\
\hline Budget & BE1 & 0,315 & 0,301 & Valid \\
Emphasis & BE2 & 0,383 & 0,301 & Valid \\
& BE3 & 0,400 & 0,301 & Valid \\
& BE4 & 0,321 & 0,301 & Valid \\
& BE5 & 0,261 & 0,301 & Tidak Valid \\
Self & BE6 & 0,115 & 0,301 & Tidak Valid \\
& SE1 & 0,141 & 0,301 & Tidak Valid \\
& SE2 & 0,185 & 0,301 & Tidak Valid \\
& SE3 & 0,357 & 0,301 & Valid \\
& SE4 & 0,368 & 0,301 & Valid \\
& SE5 & $-0,244$ & 0,301 & Tidak Valid \\
& SE6 & 0,415 & 0,301 & Valid \\
& SE7 & 0,359 & 0,301 & Valid
\end{tabular}

Partisipasi

Anggaran

SE8

0,196

0,301

Tidak Valid

SE9 $\quad 0,432$

0,301

Valid

SE10 $\quad 0,002 \quad 0,301$

Tidak Valid

0,642

0,301

Valid

PA2 0,687

0,301

Valid

PA3 0,778

0,301

Valid

PA4

0,722

0,301

Valid

PA5

0,558

0,301

Valid

PA6

0,776

0,301

Valid

Budgetary

Slack

\begin{tabular}{cccc} 
BS1 & 0,348 & 0,301 & Valid \\
BS2 & 0,331 & 0,301 & Valid \\
BS3 & 0,003 & 0,301 & Tidak Valid \\
BS4 & 0,391 & 0,301 & Valid \\
BS5 & 0,432 & 0,301 & Valid \\
BS6 & 0,385 & 0,301 & Valid \\
\hline
\end{tabular}

Sumber: Output

SPSS 16 (2019)

Hasil pada tabel 2, terdapat beberapa item yang tidak valid seperti pada item BE5, BE6, SE1, SE2, SE5, SE8, SE10, dan BS3. Item yang tidak valid ini tidak dapat dilakukan pengujian lebih lanjut dan harus dihapuskan. Setelah penghapusan item yang tidak valid maka diperoleh item pernyataan yang memiliki nilai koefisien korelasi positif dan lebih besar dari R-tabel. Hal ini berarti bahwa data yang diperoleh telah valid dan dapat dilakukan pengujian data lebih lanjut.

Tabel 3 Uji Reliabilitas

\begin{tabular}{clcc}
\hline No & Variabel & $\begin{array}{c}\text { Cronbach' } \\
\text { Alpha }\end{array}$ & Keterangan \\
\hline 1 & $\begin{array}{l}\text { Budget } \\
\text { Emphasis }\end{array}$ & 0,757 & Reliabel \\
2 & $\begin{array}{l}\text { Self Esteem } \\
\text { Partisipasi }\end{array}$ & 0,705 & Reliabel \\
3 & $\begin{array}{l}\text { Anggaran } \\
\text { Budgetary }\end{array}$ & 0,880 & Reliabel \\
4 & 0,651 & Reliabel \\
\hline
\end{tabular}

Sumber: Output SPSS 16

(2019)

Hasil pada tabel 3, menunjukkan bahwa nilai cronbach's alpha dari semua variabel lebih 


\section{PENGARUH BUDGET EMPHASIS, SELF ESTEEM, DAN PARTISIPASI ANGGARAN TERHADAP BUDGETARY SLACK PADA OPD PEMERINTAH KA BUPATEN KEBUMEN}

besar dari 0,60. Artinya instrumen dari kuesioner yang digunakan dinyatakan handal atau dapat dipercaya sebagai alat ukur variabel.

\section{Pengujian Hipotesis}

Pengujian hipotesis dalam penelitian ini dilakukan dengan menggunakan software SPSS, dengan pengujian asumsi klasik dilakukan sebelumnya. Pengujian hipotesis dilakukan menggunakan analisis regresi linear berganda. Hasil pengujian dapat dilihat pada tabel berikut:

Tabel 4 Ringkasan Pengujian Hipotesis Uji t

\begin{tabular}{lcccc}
\hline Keterangan & $\mathrm{B}$ & $\mathrm{t}$ & Sig. & Kesimpulan \\
\hline $\begin{array}{l}\text { (Constant) } \\
\text { Budget }\end{array}$ & 3.136 & 1.398 & 0.17 & \\
Emphasis & 0.335 & 2.459 & 0.018 & Diterima \\
\hline Self Esteem & 0.441 & 3.32 & 0.002 & Diterima \\
\hline $\begin{array}{l}\text { Partisipasi } \\
\text { Anggaran }\end{array}$ & 0.003 & 0.037 & 0.971 & Ditolak \\
\hline $\begin{array}{l}\text { Sumber : Output SPSS } 16 \\
\text { (2019) }\end{array}$ & & & \\
\hline
\end{tabular}

Hipotesis pertama yang diajukan dalam penelitian ini adalah Budget Emphasis berpengaruh positif terhadap Budgetary Slack. Berdasarkan hasil analisis dari uji $\mathrm{t}$ pada variabel budget emphasis, menunjukkan nilai beta sebesar 0,335 (positif) dan signifikansi variabel budget emphasis sebesar 0,018, atau mempunyai nilai signifikansi lebih kecil dari 0,05. Maka dapat disimpulkan bahwa hipotesis pertama diterima.

Hipotesis kedua yang diajukan dalam penelitian ini adalah Self Esteem berpengaruh positif terhadap Budgetary Slack. Berdasarkan hasil analisis dari uji t pada variabel Self esteem, menunjukkan nilai beta sebesar 0,441 (positif) dan signifikansi variabel self esteem sebesar 0,002 , atau mempunyai nilai signifikansi lebih kecil dari 0,05. Maka dapat disimpulkan bahwa hipotesis kedua diterima.

Hipotesis ketiga yang diajukan dalam penelitian ini adalah Partisipasi Anggaran berpengaruh positif terhadap Budgetary Slack.
Berdasarkan hasil analisis dari uji $\mathrm{t}$ pada variabel partisipasi anggaran, menunjukkan nilai nilai beta sebesar 0,003 (positif) dan signifikansi variabel partisipasi anggaran sebesar 0,971, atau mempunyai nilai signifikansi lebih besar dari 0,05. Maka dapat disimpulkan bahwa hipotesis ketiga ditolak.

Tabel 5 Ringkasan Pengujian Hipotesis Uji F

\begin{tabular}{|c|c|c|c|}
\hline Model & F & Sig. & Kesimpulan \\
\hline Regression & 6,862 & $.001^{\mathrm{a}}$ & Diterima \\
\hline
\end{tabular}

Hipotesis keempat yang diajukan dalam penelitian ini adalah Budget Emphasis, Self Esteem, dan Partisipasi Anggaran secara simultan berpengaruh terhadap Budgetary Slack. Berdasarkan hasil analisis dari uji $F$ menunjukkan bahwa nilai $\mathrm{F}$ hitung sebesar 6,862 dan nilai $F$ tabelnya sebesar 2,84 (df1=3 dan df2=43-3=40) sehingga $F$ hitung lebih besar daripada $F$ tabel. Sedangkan nilai probabilitas signifikan 0,001 lebih kecil dari 0,05. Maka model regresi dapat digunakan untuk memprediksi budgetary slack atau dapat disimpulkan bahwa hipotesis keempat diterima.

\section{KESIMPULAN}

Penelitian ini bertujuan untuk mengetahui pengaruh budget emphasis, self esteem, dan partisipasi anggaran terhadap budgetary slack pada OPD Pemerintah Kabupaten Kebumen. Hasil penelitian ini menunjukkan bahwa budgetary slack yang terjadi pada OPD Pemerintah Kabupaten Kebumen dipengaruhi oleh budget emphasis dan self esteem. Sedangkan partisipasi anggaran tidak berpengaruh terhadap timbulnya budgetary slack.

\section{SARAN}

Penelitian ini masih memiliki beberapa keterbatasan, untuk penelitian selanjutnya dapat memperluas wilayah sampel penelitian agar dapat digeneralisasikan. Diharapkan dapat menggunakan metode penelitian yang berbeda, 


\section{PENGARUH BUDGET EMPHASIS, SELF ESTEEM, DAN PARTISIPASI ANGGARAN TERHADAP BUDGETARY SLACK PADA OPD PEMERINTAH KA BUPATEN KEBUMEN}

seperti melakukan metode wawancara langsung kepada responden. menambahkan atau menggunakan variabel lainnya seperti Asimetri Informasi dalam penelitian Kusniawati dan Lahaya (2017), Komitmen Organisasi dan Ketidakpastian Lingkungan dalam penelitian Prakoso (2016), Task Complexity dalam penelitian Guswandi (2017), dan Kemampuan Pengawasan Internal dalam penelitian Suarditha et al (2017).

\section{DAFTAR PUSTAKA}

Alfebriano. 2013. Faktor-Faktor yang Mempengaruhi Slack Anggaran Pada PT. BRI di Kota Jambi. E-Jurnal Binar Akuntansi 2(1): 2303-1522.

Apriyandi. 2011. Pengaruh Informasi Asimetri Terhadap Hubungan antara Anggaran Partisipatif dengan Budgetary Slack. Skripsi. Jurusan Akuntansi Fakultas Ekonomi dan Bisnis Universitas Hasanudin. Makassar.

Ardanari, I G. A. A. S. C. dan I N. W. A. Putra. 2014. Pengaruh Partisipasi Penganggaran, Asimetri Informasi, Self Esteem dan Budget Emphasis pada Budgetary Slack. E-Jurnal Akuntansi Universitas Udayana 7(3): 700-715.

Ardianti, P. N. H., Suardikha, I M. S. dan Suputra, I D. G. D. 2015. Pengaruh Penganggaran Partisipatif pada Budgetary Slack dengan Asimentri Informasi, Self Esteem, Locus of Control dan Kapsitas Individu sebagai variabel Moderasi.E-Jurnal Ekonomi dan Bisnis Universitas Udayana 4(0):296-311.

Armaeni. 2012. Analisis Partsipasi Anggaran, Penekanan Anggaran, dan Informasi Asimetri Terhadap Senjangan Anggaran (Studi pada SKPD Pemerintah Kabupaten Pinrang). Skripsi. FEB Universitas Hasanuddin. Makasar.
Arthaswadaya, A. 2015. Pengaruh Informasi Asimetri terhadap Budgetary Slack dengan Self Esteem sebagai Variabel Pemoderasi: Studi Esperimen dalam Konteks Penganggran Partisipatif. Skripsi. Program S1 Pendidikan Akuntansi Fakultas Ekonomi Universitas Negeri Yogyakarta. Yogyakarta.

Bangun, N. dan K. W. Andani. 2012. Pengaruh Budgetary Partisipation, Information Asymmetry, Budget Emphasis dan Self Esteem Terhadap Budgetary Slack. Jurnal Akuntansi 12(1):577-594

Basyir, A. A. 2016. Pengaruh Partisipasi Anggaran, Informasi Asimetri, dan Kapsitas Individu terhadap Budgetari Slack pada SKPD Pemerintah Kota Samarinda.Jurnal Ekonomi dan Keuangan 13(2):2528-1135.

Erina, N. P. D. dan W. Suartana. 2016. Pengaruh Partisipasi Penganggaran, Penekanan Anggaran, Kapasitas Individu, Dan Kejelasan Sasaran Anggaran Pada Senjangan Anggaran. E-Jurnal Akuntansi Universitas Udayana 15(2): 973-1000.

Geografis Kabupaten Kebumen. http://kebumenkab.go.id/index.php/pub lic/page/ index/23. diunduh tanggal 10 Desember 2018 pukul 16:00 WIB.

Ghozali, I . 2014. Ekonometrika: Teori, Konsep, dan Aplikasi dengan IBM SPSS 22. Edisi Ketujuh. Cetakan Ketujuh. Badan Penerbit Universita Diponegoro. Semarang.

2016a. Aplikasi Analisis Multivariate : Dengan Program IBM SPSS 23. Edisi Kedelapan. Cetakan Kedelapan. Badan Penerbit Universitas Diponegoro. Semarang.

2018b. Aplikasi Analisis Multivariate : Dengan Program IBM 


\section{PENGARUH BUDGET EMPHASIS, SELF ESTEEM, DAN PARTISIPASI ANGGARAN TERHADAP BUDGETARY SLACK PADA OPD PEMERINTAH KA BUPATEN KEBUMEN}

SPSS 25. Edisi Kesembilan. Cetakan Kesembilan. Badan Penerbit Universitas Diponegoro. Semarang.

Guswandi, F. 2017. Pengaruh Task Complexity dan Budget Emphasis terhadap Budgetary Slack dengan Self Esteem sebagai Variabel Moderating pada SKPD di Kabipaten Bulukumba. Skripsi. Program S1 Akuntansi Fakultas Ekonomi dan Bisnis Islam UIN Alauddin. Makassar.

Hurrasyid, M. N. 2015. Pengaruh Budgetary Participation, Informasion Asymmetry, Budget Emphasis, dan Job Relevant Information terhadap Budgetary Slack Studi Empiris pada Sekolah Menengah Atas di Tangerang Selatan. Skripsi. Program S1 Jurusan Akuntansi Fakultas Ekonomi dan Bisnis Universitas Islam Negeri Syarif Hidayatullah. Jakarta.

Junaidi. 2010.Titik Persentase Distribusi F. http://junaidichaniago.wordpress.com. Diakses pada 05 Desember 2018 pukul 13:00 WIB.

Tabel Durbin Watson. http://www.standford.edu. Diakses pada tanggal 05 Desember 2018 pukul 13:30 WIB.

Kahar, S. H. A. dan A. Hormati. 2017. Peran Budget Emphasis dalam Memoderasi hubungan Partisipasi Anggaran terhadap Senjangan dan Kinerja Manajerial Studi pada 30 SKPD Kota Ternate. Jurnal Akuntansi dan Auditing 14(1):71-88.

Kusniawati, H. dan I. A. Lahaya. 2017. Pengaruh Partisipasi Anggaran, Penekanan Anggaran, Asimetri Informasi terhadap Budgetary Slack pada SKPD Kota Samarinda. Jurnal FEB Umnul 14(2): 2528-1135.

Lambang

Daerah

Kabupaten

Kebumen.http://www.kebumenkab.go.i d/index.php/ public/page/ index/21. diunduh tanggal 4 januari 2019 pukul 16:18 WIB.

Mulyani, R. A. 2015. Pengaruh Partisipasi Penyusunan Anggran Terhadap Senjangan Anggaran dengan Budget Emphasis sebagai Variabel Moderasi : Studi Kasus pada Pemerintah Kota Cirebon. Skripsi. Program S1 Fakultas Pendidikan Ekonomi dan Bisnis Universitas Pendidikan Indonesia. Bandung.

Mulyani, S. dan F. A. Rahman. 2012. Pengaruh Partisipasi Penganggaran, Tekanan Anggaran, Komitmen Organisasi dan Kompleksitas Tugas Terhadap Slack Anggaran Pada Perbankandi Pekanbaru. Jurnal Ekonomi, Manajemen dan Akuntansi I 18(1): 4362.

Nopriyanti, E., N. Azlina, dan M. Alamsyah. 2016. Pengaruh Partisipasi Anggaran, Penekanan Anggaran, Komitmen Organisasi, Locus of Control, dan Kompleksitas Tugas Terhadap Kesenjangan Anggaran (Studi Empiris pada SKPD Kabupaten Agam). JOM Fekon 3(1): 777-791.

Prakoso, R. W. 2016. Analisis Pengaruh Partisipasi Anggaran, Informasi Asimetri, Komitmen Organisasi, dan Ketidakpastian Lingkungan Terhadap Senjangan Anggaran : Studi Kasus pada SKPD Kota Semarang. Skripsi. Program S1 Akuntansi Fakultas Ekonomi Universitas Negeri Semarang. Semarang.

Resen, N. S. K. 2014. Pengaruh Partisipasi Anggaran, Self Esteem, dan Budget Emphasis Terhadap Budgetary Slack Pada Hotel Berbintang di Denpasar. EJournal Akuntansi Universitas Udayana 10(1): 2302-8556.

Savitri, E. dan E. Sawitri. 2014. Pengaruh Partisipasi Anggaran, Penekanan 


\section{PENGARUH BUDGET EMPHASIS, SELF ESTEEM, DAN PARTISIPASI ANGGARAN TERHADAP BUDGETARY SLACK PADA OPD PEMERINTAH KA BUPATEN KEBUMEN}

Anggaran dan Informasi Asimetri Terhadap Timbulnya Kesenjangan Anggaran. Jurnal Akuntansi 2(2): 210226.

Sejarah

Kabupaten

Kebumen.http://kebumenkab.go.id/inde x.php/public/page/ index/20 diunduh pada tanggal 10 Desember 2018 pukul 16:20 WIB.

Setiyanto, A. B. 2011. Pengaruh Informasi Asimetri dan Partisipasi Penganggaran terhadap Komitmen Organisasi serta Dampaknya terhadap Timbulnya Senjangan Anggaran Studi Kasus pada PT. Suara Merdeka Perss Semarang. Skripsi. Program S1 Akuntansi Fakultas Ekonomi Universitas Diponegoro. Semarang.

Soleh, C. dan H. Rochmansjah. 2010. Pengelolaan Keuangan dan Aset Daerah. Fokusmedia. Bandung.

Suarditha, N. G., A.A.N.B. Dwirandra dan D. N. Badera. 2017. Kemampuan Pengawasan Internal dan Gaya Kepemimpinan Memoderasi Pengaruh Partiaipasi Penganggaran dan Profesionalisme pada Senjangan Anggaran Pemerintah Provinsi Bali. EJurnal Ekonomi dan Bisnis Universitas Udayana 6(3):1205-1232.

Triana, M., Yuliusman dan W. E. Putra. 2012. Pengaruh Partisipasi Anggaran, Budget Emphasis, dan Locus of Control Terhadap Slack Anggaran (Survei Pada Hotel Berbintang di Kota Jambi). eJurnal Binar Akuntansi 1(1): 51-60.

Undang-Undang Republik Indonesia Nomor 9 Tahun 2015. Pemerintah Daerah. 2003.

Visi dan Misi Kabupaten Kebumen.http://www.kebumenkab.go.i d/index.php/ public/page/index /19 diunduh pada tanggal 10 Desember 2018 pukul 16:30 WIB.

Wati, C. H. S., Teturan, Y. E. dan Maspaitella, N. F. 2013. Pengaruh Partisipasi Anggaran dan Budget Emphasis terhadap Budgetary Slack Pada Telkom Di Kota Merauke. Jurnal Ilmu Ekonomi dan Sosial 4(1).

Wati, N. P. D. L. S. dan I G. A. E. Damayanthi. 2017. Pengaruh Partisipasi Penganggaran, Asimetri Informasi, Ketidakpastian Lingkungan dan Budget Emphasis pada Senjangan Anggaran. E-Jurnal Akuntansi Universitas Udayana 21(3):2311-2337.

Yuwono, S., Dkk. 2005. Penganggran Sektor Publik Pedoman Praktis Penyusunan, pelaksanaan, dan Pertanggungjawaban APBD (Berbasis Kinerja). Bayumedia Publishing. Malang. 